\title{
A longitudinal study of adult-onset asthma incidence among HMO members
}

\author{
Susan R Sama*1, Phillip R Hunt ${ }^{1}$, CIH Priscilla Cirillo², Arminda Marx¹, \\ Richard A Rosiello ${ }^{3}$, Paul K Henneberger ${ }^{5}$ and Donald K Milton ${ }^{1,4}$
}

\begin{abstract}
Address: ${ }^{1}$ Department of Environmental Health, Harvard School of Public Health, Boston, MA, USA, ${ }^{2}$ Research Department, Fallon Clinic, Worcester, MA; USA, ${ }^{3}$ Department of Pulmonary and Critical Care Medicine, Fallon Clinic, Worcester, MA, USA, ${ }^{4}$ Department of Occupational Medicine, Fallon Clinic, Worcester, MA, USA and ${ }^{5}$ Division of Respiratory Disease Studies, National Institute for Occupational Safety and Health, Morgantown, WV, USA

Email: Susan R Sama* - ssama@hsph.harvard.edu; Phillip R Hunt - prhunt@hsph.harvard.edu; CIH Priscilla Cirillo - priscilla.cirillo@fallonclinic.com; Arminda Marx - mmarx@hsph.harvard.edu; Richard A Rosiello - richard.rosiello@fallon-clinic.com;

Paul K Henneberger - pkh0@cdc.gov; Donald K Milton - dmiltion@hsph.harvard.edu

* Corresponding author
\end{abstract}

Published: 07 August 2003

Environmental Health: A Global Access Science Source 2003, 2:10

This article is available from: http://www.ehjournal.net/content/2/1/10

(c) 2003 Sama et al; licensee BioMed Central Ltd. This is an Open Access article: verbatim copying and redistribution of this article are permitted in all media for any purpose, provided this notice is preserved along with the article's original URL.

Received: 03 April 2003

Accepted: 07 August 2003

\begin{abstract}
Background: HMO databases offer an opportunity for community based epidemiologic studies of asthma incidence, etiology and treatment. The incidence of asthma in HMO populations and the utility of $\mathrm{HMO}$ data, including use of computerized algorithms and manual review of medical charts for determining etiologic factors has not been fully explored.

Methods: We identified adult-onset asthma, using computerized record searches in a $\mathrm{New}$ England HMO. Monthly, our software applied exclusion and inclusion criteria to identify an "at-risk" population and "potential cases". Electronic and paper medical records from the past year were then reviewed for each potential case. Persons with other respiratory diseases or insignificant treatment for asthma were excluded.
\end{abstract}

Confirmed adult-onset asthma (AOA) cases were defined as those potential cases with either newonset asthma or reactivated mild intermittent asthma that had been quiescent for at least one year. We validated the methods by reviewing charts of selected subjects rejected by the algorithm.

Results: The algorithm was 93 to $99.3 \%$ sensitive and $99.6 \%$ specific. Sixty-three percent $(n=469)$ of potential cases were confirmed as AOA. Two thirds of confirmed cases were women with an average age of 34.8 (SD II.8), and $45 \%$ had no evidence of previous asthma diagnosis. The annualized monthly rate of AOA ranged from 4.1 to II.4 per 1000 at-risk members. Physicians most commonly attribute asthma to infection (59\%) and allergy (14\%). New-onset cases were more likely attributed to infection, while reactivated cases were more associated with allergies. Medical charts included a discussion of work exposures in relation to asthma in only $32(7 \%)$ cases. Twentythree of these $(72 \%)$ indicated there was an association between asthma and workplace exposures for an overall rate of work-related asthma of $4.9 \%$.

Conclusion: Computerized HMO records can be successfully used to identify AOA. Manual review of these records is important to confirm case status and is useful in evaluation of provider 
consideration of etiologies. We demonstrated that clinicians attribute most AOA to infection and tend to ignore the contribution of environmental and occupational exposures.

\section{Background}

Asthma is a seriously debilitating and sometimes lifethreatening disease that affects more than 8 million adults in the United States. [1] The incidence, prevalence and mortality of this disease appear to be increasing, as does the incidence of occupational asthma. [2-5] Estimates of incidence rates of asthma in adults range between 0.54.1/1,000 at-risk per year. [5-7]

Health maintenance organization (HMO) member populations offer a unique opportunity for community-based epidemiologic studies of asthma. [8-12]

Computerized HMO data have been successfully used to study asthma, though most research has focused on prevalence or drug therapy. Donahue and colleagues conducted a study using automated medical records from an HMO in eastern Massachusetts to determine the reliability of identifying asthmatics and determining severity of asthma in computerized medical and pharmacy records. [10] They conducted a review of full text medical records on a random sample of identified cases to validate asthma diagnosis and to extract clinical information that was used to assess asthma severity. Full text medical record review demonstrated a positive predictive value of $86 \%$ for those identified by the automated method for coded asthma diagnosis, but researchers found limited utility of these data to assess disease severity. They demonstrated modest agreement between computerized and manual methods to determine incident versus prevalent asthma (kappa = 0.5 ) and that occupation was noted in only $19 \%$ of records reviewed.

Our study provides additional evidence that computerized data in HMO systems can be used successfully to measure asthma incidence; that review of clinical data from staff model HMO medical records is valuable in confirming asthma diagnosis, when using computerized algorithms for case identification; and that HMO medical records can provide some detail on the evaluation of medical care and how often clinicians document and use relevant information on etiologic factors, including relevant workplace exposures.

In this paper we report the incidence of AOA (both newonset and a reactivated asthma) in a New England HMO. We also evaluate the usefulness of conducting reviews of medical records to validate case status and report the frequency that clinicians obtained and used relevant etiologic data for cases.

\section{Methods \\ Study population}

Fallon Community Health Plan (FCHP) provides health care services through the Fallon Clinic, a centralized organization that provides the full range of services to FCHP members with over 300 physicians working at more than 30 ambulatory care centers in central Massachusetts. In 2000, it served approximately 190,000 people. Virtually all (99\%) FCHP members are enrolled without health screening either through employer-based programs $(83 \%)$ or Medicaid and Medicare contracts (16\%). Thus, there are no health-based barriers to membership for employed persons and their families. Fallon is offered by about 3,500 employers. Most of the self-pay members have converted temporarily to this status on leaving employment. In addition, the clinic offers fee-forservice medical care to non-members.

\section{Case identification}

This investigation was reviewed and approved by the Fallon Institutional Review Board, as well as the Harvard School of Public Health Human Subjects Committee. Software to query the HMO's Oracle ${ }^{\circledast}$ data warehouse of coded outpatient encounter forms and inpatient and referral claims was developed and a study algorithm was designed to identify potential cases of adult-onset asthma (AOA) similar to a previously described algorithm used on an older computer system [Milton, 1998]. Automated searches were performed on a monthly basis. For each month, the algorithm first applied membership criteria to obtain eligible members, followed by exclusion criteria to identify an at-risk population, and finally by inclusion criteria to identify potential cases.

Data for each month were first queried approximately 2 weeks after the last day of the month, and queried monthly thereafter for 6 months to ensure that late-arriving claims data were included. The membership criteria ensured that the study population had comparable quality of information by requiring that eligible members for a given month (the index month) a) had at least 6 months of HMO membership with no gap of more than 45 days in coverage prior to the index month and b) had been a member for the entire index month. Because inclusion and exclusion criteria were based on prescription information and were confirmed by chart review, the study population was also restricted to those members with plan types that included pharmacy benefits and primary care delivered through the staff model portion of the HMO the Fallon Clinic. Enrollment in the cohort was open to 
Table I: Exclusion criteria used to identify at-risk population*

\begin{tabular}{lll}
\hline & Description & ICD-9 (CPT) Codes $\dagger$ \\
\hline 1 & Heart Failure & $428-428.9$ \\
2 & Bronchitis, chronic bronchitis, and emphysema & $490-492.8$ \\
3 & Pulmonary hypertension, embolism and other pulmonary heart disease & $415-416.9$ \\
4 & Chronic obstructive pulmonary disease & 496 \\
5 & ER visit or hospital admission for primary asthma diagnosis & $493-493.91$ \\
6 & Occupational asthma diagnosis & $504-507,495.8,507.8$ \\
7 & Asthma diagnosis AND outpatient nebulization treatment & $493-493.91$ AND (94640) \\
8 & Ordered second line asthma medications ${ }^{\ddagger}$ & $493-493.91$ \\
9 & Any asthma diagnosis AND ordered oral steroids & $493-493.91$ \\
10 & Asthma diagnosis AND ordered 4 or more MDIs &
\end{tabular}

* Exclusion criteria were applied to records for the 12 months preceding the index month. IInternational Classification of Diseases 9 th Edition and Current Procedural Terminology codes; ¥ Second line medications included cromolyn, necrodomyl, aerosolized steroids, theophylline, oral or nebulized Beta-agonists, and leukotriene inhibitors; TMDI= Beta-agonist metered dose inhaler.

ensure that new members were included six months after joining the health plan and that they contributed person time to the study until termination of insurance coverage. Males and females between ages 15 and 55 were eligible for inclusion in the study population.

Exclusion criteria (Table 1) were applied in the computerized search of encounter forms, claims, and pharmacy data from the twelve months (reference period) prior to each index month to define the "at-risk" population. Exclusion criteria were designed to remove members with prevalent asthma and various co-morbid conditions such as bronchitis, chronic bronchitis, chronic obstructive pulmonary disease, chronic and acute pulmonary heart disease, and pulmonary hypertension from the "at-risk" population. Prevalent asthma was defined as having a record of asthma admission, by dispensing of second line medications, or an outpatient visit for asthma with either a nebulization treatment, or dispensing of oral steroids or more than four metered dose inhalers.

The final step in the algorithm applied several inclusion criteria to computerized records regarding the "at-risk" population for the current (index) month to identify the "potential cases", all of which were subjected to a medical chart review by trained research nurses and/or a respiratory epidemiologist. The inclusion criteria included an emergency room visit or hospital admission with a primary diagnosis of asthma, diagnosis of occupational asthma or an outpatient asthma diagnosis in conjunction with clinically significant pharmacological treatment for asthma (Table 2). AOA was defined as an asthma case, verified by manual chart review, who either had onset of asthma (with no prior history of asthma) or reactivation of asthma that had been quiescent for at least one year.

\section{Chart review}

Confirmation of case status by manual review of the medical record was incorporated into the study design to provide specificity so that initial case identification by the computerized algorithm would be highly sensitive. Medical records (both electronic and hard-copy charts) of all potential cases were reviewed by a trained research nurse and the findings recorded in a computerized database. Three percent of charts were either missing or had insufficient data on which to determine asthma status. The chart review covered a 13-month period, beginning with the month of selection into the cohort (index period) followed by review of the 12 months preceding that date (reference period). Records for the index period were reviewed to identify and evaluate the adequacy of a casedefining event. We considered an adequate case-defining event to exist when a physician recorded an asthma diagnosis in the written record, and there was clinically significant asthma treatment prescribed and ordered within a month of the diagnosis. The chart reviewer also looked for exclusion criteria by reviewing the medical records for the reference period. A case was confirmed when a subject met any of the inclusion criteria during the index period without meeting any exclusion criterion during the 12 months prior. Asthma severity was used to define the distribution of asthma cases that were selected by the computerized algorithm and to evaluate the accuracy of the algorithm. It also assisted with proper AOA case identification. Asthma severity was assessed using National Heart, Lung and Blood Institute guidelines adapted for use with the information available in the medical record (Table 3). [1]

In addition to evaluation of inclusion and exclusion criteria, the chart reviewer recorded several other factors to the extent that they appeared in the chart during the time interval covered by the chart review. These included: the 
Table 2: Inclusion criteria used to identify adult-onset asthma cases*

\begin{tabular}{lll}
\hline & Criteria & ICD-9 (CPT) Codes ${ }^{\dagger}$ \\
\hline 1 & Asthma diagnosis AND outpatient nebulization treatment & $493-493.91$ AND (94640) \\
2 & Any asthma diagnosis AND ordered oral steroids & $493-493.91$ \\
3 & Any asthma diagnosis AND a second line medication $\ddagger$ & $493-493.91$ \\
4 & ER visit OR hospital admission for primary asthma diagnosis & $493-493.91$ \\
5 & Asthma diagnosis AND $\geq 2$ MDIs & $493-493.91$ \\
6 & Occupational asthma diagnosis & $504-507,495.8,507.8$ \\
\hline
\end{tabular}

* Inclusion criteria were applied to records during the index month, $\dagger \ddagger$ ISSee Table I

Table 3: Categories for classifying potential cases selected for chart review

\begin{tabular}{|c|c|c|c|c|}
\hline \multicolumn{5}{|c|}{ Classification of Asthma Severity } \\
\hline & Symptoms & Night time Symptoms & Lung Function & Chart Review \\
\hline \multirow[t]{3}{*}{ Mild Intermittent } & - Symptoms $\leq 2$ times/week & $\leq 2$ times a month & - $\mathrm{FEV}$, or $\mathrm{PEF} \geq 80 \%$ predicted & $\begin{array}{l}\text { Asthma not mentioned in visits that are } \\
\text { routine (i.e. physical exam) or for other } \\
\text { medical problems. Does not refill } \\
\text { asthma medications regularly. }\end{array}$ \\
\hline & $\begin{array}{l}\text { - Asymptomatic and normal PEF } \\
\text { between exacerbations }\end{array}$ & & - PEF variability $<20 \%$ & \\
\hline & $\begin{array}{l}\text { - Exacerbations brief (from a few hours } \\
\text { to a few days); intensity may vary }\end{array}$ & & & \\
\hline \multirow[t]{2}{*}{ Mild Persistent } & $\begin{array}{l}\text { - Symptoms }>2 \text { times a week but }<1 \\
\text { time a day }\end{array}$ & $>2$ times a month & - $F E V_{\text {, }}$ or $\mathrm{PEF} \geq 80 \%$ predicted & $\begin{array}{l}\text { Asthma mentioned in some of the } \\
\text { "non-asthma" visits. Asthma meds } \\
\text { refilled regularly. Exacerbation may } \\
\text { require systemic steroids. }\end{array}$ \\
\hline & - Exacerbations may affect activity & & - PEF variability $20-30 \%$ & \\
\hline \multirow[t]{4}{*}{ Moderate Persistent } & - Daily Symptoms & $>$ I time a week & - $\mathrm{FEV}_{1}$ or $\mathrm{PEF}>60 \%-<80 \%$ predicted & $\begin{array}{l}\text { Asthma is a common reason for visits. } \\
\text { Uses inhaled steroids regularly. Uses } \\
\text { systemic steroids intermittently, but } \\
\text { more than once a year in most years. }\end{array}$ \\
\hline & $\begin{array}{l}\text { - Daily use of inhaled short-acting } \\
\text { beta2-agonist }\end{array}$ & & - PEF variability $>30 \%$ & \\
\hline & - Exacerbations affect activity & & & \\
\hline & $\begin{array}{l}\text { Exacerbations } \geq 2 \text { times a week; may } \\
\text { last days }\end{array}$ & & & \\
\hline \multirow[t]{3}{*}{ Severe Persistent } & - Continual symptoms & Frequent & - $\mathrm{FEV}$, or $\mathrm{PEF} \leq 60 \%$ predicted & $\begin{array}{l}\text { Asthma always a problem. Systemic } \\
\text { steroids frequently or continuously. } \\
\text { Hospitalizations. }\end{array}$ \\
\hline & - Limited physical activity & & - PEF variability $>30 \%$ & \\
\hline & - Frequent exacerbations & & & \\
\hline
\end{tabular}

Adapted from NHLBI "Guidelines for the diagnosis and management of asthma". NIH publication number 97-405I, July I997.

physician's level of documentation and certainty of asthma diagnosis, presence and result of methacholine challenge testing, etiology of asthma as recorded by practitioners, presence and relevant content of an annual physical examination, prescription of respiratory medications, pulmonary tests ordered in the past year (spirometry, serial peak expiratory flows), history of childhood asthma, height, weight and demographic information. The presence of notes that evaluated symptoms in relation to home, work and environmental exposures were also recorded along with the type of practitioner making the record.
To measure the sensitivity of the computerized records search, we performed an additional analysis to identify possible adult-onset asthma cases that may have been missed by our algorithm. We therefore, focused on eligible members with asthma diagnoses to increase the possibility of identifying cases that may have been excluded in error. We first applied our exclusion and inclusion criteria and performed chart reviews as described above. We then made a second run over the data with altered exclusion criteria so that we did not exclude persons with prior asthma or acute bronchitis; thus, obtaining an at-risk population containing all asthmatics who did not have heart failure, chronic bronchitis, emphysema, chronic obstruc- 


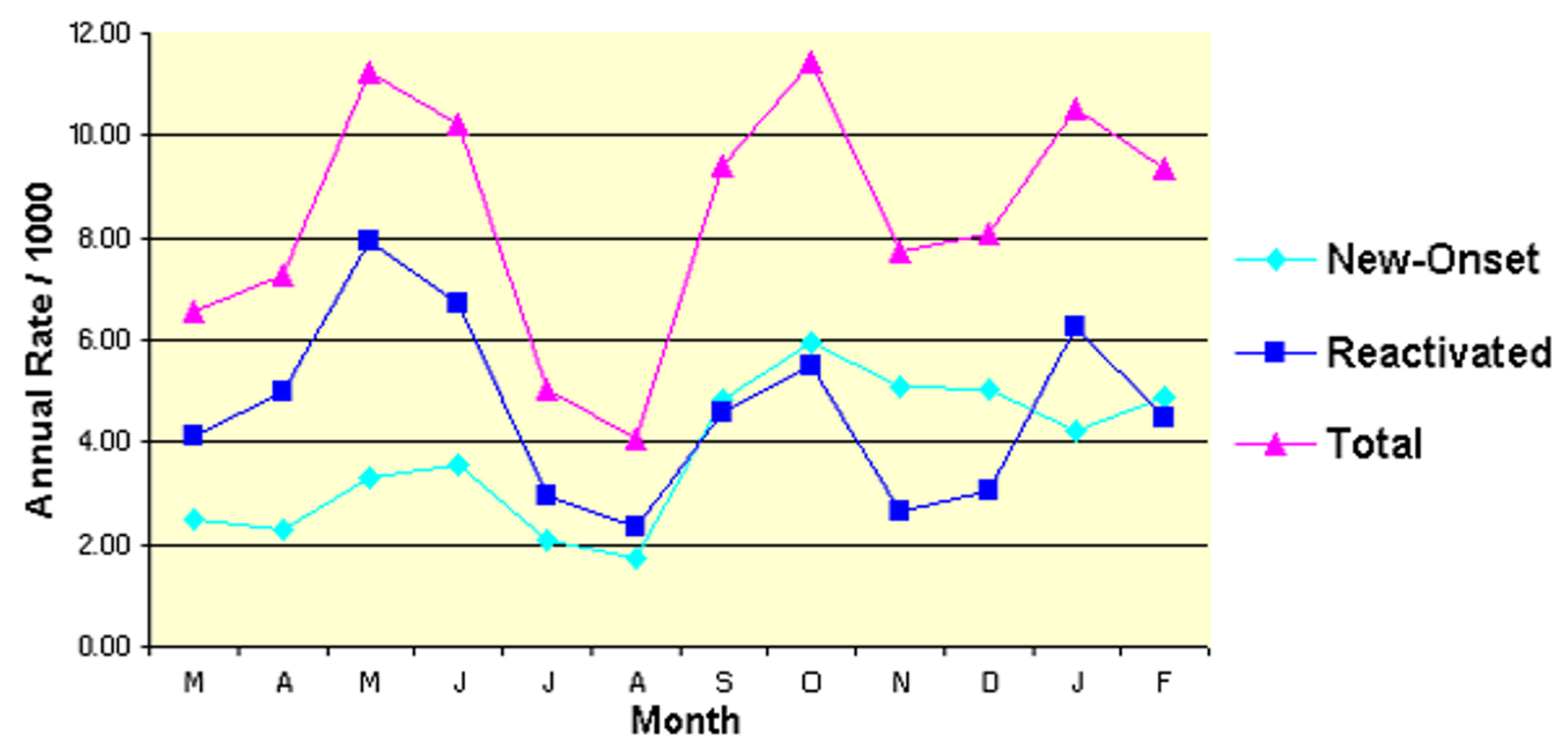

Figure I

Annualized adult-onset asthma incidence-March 2000-February 200 I

tive lung disease, pulmonary hypertension, embolism, or other pulmonary heart disease. From this group, we excluded all cases accepted after the chart review described above. We then applied our inclusion criteria, except that we altered criterion number 5 so that at-risk members with an asthma diagnosis and one MDI were included. All charts of the new cases so identified were subjected to chart review.

\section{Data analysis}

Chart reviews were recorded in Microsoft Access file format using a computerized questionnaire system (CSESC, Boston, MA) and converted into SAS datasets (version 8 , SAS Institute, Cary, NC) for data analysis using SAS Proc Freq and SAS Proc Means. EpiInfo6 and Statcalc were used to calculate relative risks and confidence intervals.

\section{Results}

\section{Summary of cohort and incidence data}

The monthly average eligible population consisted of 61,892 HMO members including 55,905 at-risk of developing asthma. The monthly, computerized searches identified 746 potential cases for the 12-month period March 2000 through February 2001. On average, 62 potential cases were identified each month and 39 were confirmed by chart review. The incidence of confirmed AOA varied by month and trends for new-onset and reactivated asthma were similar (Figure 1). The incidence over the one-year study period was 3.8 per 1000 persons for newonset cases, 4.6 per 1000 for reactivation of asthma after at least one year of inactivity and 8.4 per 1000 combined.

Overall, three seasonal AOA peaks were observed in the combined (new onset and reactivation) annualized rates: May - June, September - October, and January-February. July and August had the lowest combined AOA incidence rates. Rates of new onset and reactivation were roughly equal in August through October 2000. Reactivation rates were greater than new onset rates from March through July 2000 and in January 2001. New onset rates were greater than reactivation rates during the months of November, December 2000 and February 2001.

\section{Validation of computerized exclusions and inclusions}

We performed several analyses using chart reviews of both paper and electronic medical records to determine the validity of the exclusion and inclusion of HMO members as executed by the computerized algorithm. The validity necessarily depends on the quality of the data in the computer system, and the evaluation depends on the completeness of data in the hard copy medical record and electronic doctors' notes used for comparison. Initial tests of validity included chart reviews for randomly selected 
Table 4: Case confirmation rates by algorithm inclusion criteria

\begin{tabular}{lcr}
\hline Criteria & Potential Cases & Confirmed Cases \\
& & N \\
\hline Asthma diagnosis AND outpatient nebulization treatment & 185 & 148 \\
Any asthma diagnosis AND ordered oral steroids & 156 & 80 \\
Any asthma diagnosis AND a second line medication $\ddagger$ & 305 & 67 \\
ER visit OR hospital admission for primary asthma diagnosis & 38 & 105 \\
Asthma Diagnosis AND $\geq 2$ MDIs & 49 & 175 \\
Occupational asthma diagnosis & 13 & 20 \\
Total & 746 & 18 \\
\end{tabular}

charts of excluded members. No erroneously excluded members were found.

To determine the sensitivity of the computerized records search for AOA, we examined data from an overlapping study of prevalent asthmatics from the same HMO during the ten-month period September 2000 to June 2001. The computer search for prevalent asthmatics included all persons, who did not have a chronic disqualifying ailment other than asthma and had not been included in the AOA study, but who had a computer record of asthma treatment during this time period. There were an average of 59,920 eligible members during this time period and an at-risk population of 54,090 for the AOA study with 629 potential and 399 accepted AOA cases after chart review. There were 85 persons identified by the computer search for prevalent asthma identified who were not identified by the search for AOA. Review of these charts showed that 82 had persistent asthma, mild intermittent asthma without exacerbation, or were judged as not asthma based on chart review. Three of the 85 cases met our criteria for adult-onset asthma.

We estimated sensitivity and specificity of the computer search for AOA by assuming that the 3 cases identified as erroneously excluded represented all of such cases. Under this assumption, the computer algorithm for possible adult-onset asthma was $99.3 \%$ (399/402) sensitive and $99.6 \%(59,288 / 59,518)$ specific. Even if we were to assume that these 3 cases only accounted for $10 \%$ of erroneously excluded cases, the sensitivity of the computer algorithm remains high (93\%). However, the positive predictive value of the computer algorithm was only (399/ 629) $63 \%$ during the ten month validation period.

During the one year of complete data collection reported here, sixty-three percent $(n=469)$ of all potential cases identified by the computer algorithm were confirmed by chart review. The confirmation rates for each of the six inclusion criteria are shown in Table 4. The most specific inclusion criteria were asthma diagnosis with a nebulizer treatment $(80 \%)$, and asthma diagnosis with a prescription for oral steroids (66\%). Asthma status in the 12 months prior to the index month was also assessed by chart review and is shown in Table 5. The majority of cases rejected by chart review had persistent asthma with symptoms during the previous 12 months $(\mathrm{n}=100)$, weak evidence of asthma $(\mathrm{n}=58)$ or mild intermittent asthma with no exacerbation during the index month $(\mathrm{n}=35)$. One potential case with new-onset asthma and 20 potential cases classified as mild intermittent asthma had comorbid lung conditions or significant asthma treatment in the previous 12 months that had not been captured by the computerized records search.

\section{Observations on adult-onset asthma}

Approximately two-thirds of all confirmed cases of adultonset asthma were women with an average age of 34.8 (SD 11.8) (Table 5). The average age in males was similar (34.6; SD 12.2). Overall, clinicians attributed asthma onset in most cases (59\%) to infection (Table 6). Newonset cases however, were more likely to be attributed to infection $(\mathrm{RR}=1.4,95 \%$ C.I. $1.2,1.6)$ than were reactivated cases, and less likely to be attributed to allergies (RR $=0.54,95 \%$ C.I. 0.32, 0.89). Ten percent of cases had a history of childhood asthma (based on notes in the medical records from the last 13 months), and an additional 18 percent had notes indicating asthma onset more than a year before the case-defining event.

Peak expiratory flow rates, the most frequently recorded measure of pulmonary function in the year prior to case identification, were performed by $39 \%(n=181)$ of accepted cases. Spirometry was recorded in only $2 \%(\mathrm{n}=$ 11) of cases while spirometry pre- and post-bronchodilator was slightly less frequent $(1.5 \%, \mathrm{n}=7)$. Methacholine challenge testing was administered to 1 case.

\section{Provider Consideration of Exposures in Confirmed Cases}

Providers noted potential environmental/outdoor, home and occupational exposures in notes about asthma in only a small fraction of cases (Table 7). When noted, 
Table 5: Demographics and asthma status for potential, excluded and confirmed cases

\begin{tabular}{|c|c|c|c|}
\hline & Potential Cases & Excluded Cases & Confirmed Cases \\
\hline Female $n,(\%)$ & $483(65)$ & $176(64)$ & $307(66)$ \\
\hline Age, female mean (SD) & $34.4(12)$ & $33.5(12)$ & $34.8(12)$ \\
\hline Males & $263(35)$ & I0I (37) & $162(35)$ \\
\hline Age, male mean (SD) & $34.2(12)$ & $33.6(12)$ & $34.6(12)$ \\
\hline \multicolumn{4}{|c|}{ Asthma Status Prior to Index Month n, (\%) } \\
\hline No Prior Asthma & $211(28)$ & $\mathrm{I}(<1 \%)$ & $210(45)$ \\
\hline Mild Intermittent, Inactive & $279(37)$ & $20(7)$ & $259(55)$ \\
\hline Mild Intermittent, Active & $39(5)$ & $39(14)$ & 0 \\
\hline Mild Persistent with Exacerbation & $62(8)$ & $62(22)$ & 0 \\
\hline Mild Persistent & $31(4)$ & $31(11)$ & 0 \\
\hline Moderate Persistent & $7(1)$ & $7(3)$ & 0 \\
\hline Weak Evidence & $58(8)$ & $58(21)$ & 0 \\
\hline No Evidence & $35(5)$ & $35(13)$ & 0 \\
\hline Insufficient Data & $24(3)$ & $24(9)$ & 0 \\
\hline Total & 746 & 277 & 469 \\
\hline
\end{tabular}

Table 6: Clinician assessment of cause of asthma onset

\begin{tabular}{lllll}
\hline Cause of Morbidity* & Total Cases, N (\%) & New-onset Cases N (\%) & Reactivated Cases N (\%) & Relative Risk,** [95\% C.I.] \\
\hline Infection Induced & $275(59)$ & $144(70)$ & $131(5 \mathrm{I})$ & $1.4,[1.2,1.6]$ \\
Allergy Induced & $63(14)$ & $19(9)$ & $44(17)$ & $0.54,[0.32,0.89]$ \\
Exercise Induced & $20(4)$ & $9(4)$ & $11(4)$ & $1.02,[0.43,2.41]$ \\
Other & $23(5)$ & $12(6)$ & $11(4)$ & $1.36,[0.61,3.02]$ \\
No Etiology Given & $84(18)$ & $23(11)$ & $61(24)$ & $0.47,[0.30,0.73]$ \\
Total & $465^{*}$ & 207 & 258 &
\end{tabular}

*4 missing observations **Unadjusted Relative Risk, New-onset cases versus reactivated cases with reference group representing all other etiologic categories combined, including "no etiology given"

Table 7: Frequency of exposures mentioned in medical records of confirmed cases.

\begin{tabular}{llll}
\hline & Occupational Exposures, $\mathbf{N}(\%)$ & Home Exposures, $\mathbf{N}(\%)$ & $\begin{array}{l}\text { Environmental/Outdoor } \\
\text { Exposures, } \mathbf{N}(\%)\end{array}$ \\
\hline $\begin{array}{l}\text { Confirmed cases with noted exposure } \\
\text { Positive Association Noted }\end{array}$ & $32(7)^{*}$ & $53(11)$ & $61(13)$ \\
\hline
\end{tabular}

*Percent of all confirmed cases $(n=469)$. **Percent of confirmed cases with positive association noted for respective exposures

however, environmental/outdoor and home exposures were reported as asthma triggers (but not necessarily causal agents) in $72 \%$ and $66 \%$ of respective cases. Of patients asked about work-related exposures, $72 \%$ were noted to have work-related asthma (4.9\% of all AOA). Occupation was recorded at sometime during the 13month interval covered by the chart review for $22 \%$ of AOA patients. Of the 23 with patients whose charts indicated that they had work-related asthma, three were coded by providers on encounter forms as having occupational asthma and two of these were seen by an occupational medicine specialist.

\section{Discussion}

This study demonstrates that we can successfully identify adult-onset asthma in HMO data with high sensitivity and specificity, but that the high sensitivity is gained at the expense of a relatively low predictive value positive necessitating manual chart review of potential cases. 
These data also suggest that chart review is necessary to distinguish between new-onset and reactivated asthma.

An earlier study conducted by Donahue and colleagues [10] focused on measuring disease severity for analysis of quality of care but did not present results on the sensitivity and specificity of their automated search. Their finding that manual review of medical records, combined with an automated search of HMO data were necessary to distinguish between incident and prevalent asthma is consistent with ours.

Our data show that clinicians tend to overlook or at the very least, fail to document the potential contributions of environmental and occupational etiology in most cases. Occupational asthma incidence rates are sparse in studies conducted in the United States. In addition, there has long been anecdotal evidence that physicians do not adequately assess the work-relatedness of many diseases, including asthma. These data support that claim. Donahue's study similarly demonstrated that common sources of asthma incitants (pets, passive smoke, workplace exposures) were rarely documented in medical records of asthmatics. They show that occupation was noted in $19 \%$ of reviewed cases.

The overall incidence of new-onset asthma and asthma reactivation in adults in this population were higher during the period of observation reported here from March of 2000 through February of 2001 (3.8/1,000 for new-onset asthma and 4.6/1,000 for reactivated asthma) than the rate observed in the three-month pilot study in 1995 (1.3/ 1,000 for new-onset asthma and 2.4/1,000 for reactivated asthma). [12] There appears to be almost a three-fold increase in the new-onset cases and a two-fold increase in reactivated cases of asthma. This increase persists when considering only the same three months observed in the pilot study (July through September), though it is somewhat less strong, especially for reactivated asthma. There are many possible explanations for this observation. The two to three-fold interval change in rates may represent improved or more complete data capture by the data warehouse compared with older computer systems used previously, and cannot be attributed to increased incidence alone.

Epidemiologic investigations typically demonstrate higher rates of asthma later in life in women than in men, as seen in these data. [13-15] The mean age at onset of AOA within the studied age range does not differ between men and women.

Our findings regarding the very small number of cases who had evidence of spirometry with or without pre- and post-bronchodilator testing or methacholine challenge testing was also consistent with the observations of Donahue and colleagues. [10] They report that spirometry was associated with only one percent of encounters. Peak expiratory flow measurement, however, was reported more frequently in this population than that observed by Donahue et al. (39\% versus 4\%). The reason for this is unclear. It is possible that review of hard copy charts conducted at Fallon provides more complete data with regards to peak expiratory flow rates often used in urgent care centers to evaluate the effectiveness of nebulizer treatments. There could well be cultural differences between HMO's and incentives for recording various treatments.

In general, clinicians attributed AOA primarily to infection and less often to allergy. Annualized rates of new onset asthma were greater during the fall and winter months (September through February). This may represent the influence of certain infections during the winter months on new-onset cases consistent with the clinical attribution of most new onset cases to infection. On the other hand, the months with peak reactivation rates in May through June suggest that allergies may play a more important role in reactivation, consistent with the clinical impressions recorded by providers. Alternatively, the National Heart, Lung and Blood Institute's effort to increase the use of lung function testing to improve proper diagnosis of asthma may have had an impact over the 10 years since the Donahue data were collected. [16]

It appears that providers seldom recorded information about occupation in notes on asthma unless they considered the symptoms triggered by workplace exposures. Records indicated that only $7 \%$ of members with AOA were asked about work-related exposures in relation to asthma symptoms, but because $72 \%$ of these were reported as having an association with work it seems likely that clinicians asked more often but seldom documented it unless the answer was positive. Home, outdoor and other environmental exposures were also rarely recorded or discussed by providers. If recorded, these exposures were also likely to be reported as being related to symptoms. Although not surprising, it is nevertheless disappointing to find such a dearth of exposure information noted in medical charts. It seems providers do not have a thorough or systematic approach to evaluating various exposures in relation to new asthma symptoms. It is, however possible that providers only record positive associations or asthma triggers in medical notes and disregard areas that may have been discussed but seemed not to bear a causal or exacerbating role.

Almost 5\% of adult-onset asthma cases were recognized as having work-related symptoms. This gives an annual work-related symptoms incidence among adult-onset cases of 40/100,000 HMO members. This places a lower- 
bound on the actual incidence of work-related asthma in this central Massachusetts population of HMO members.

\section{Conclusions}

In summary, we demonstrate that computerized $\mathrm{HMO}$ databases (computerized search with manual medical chart review) can be used successfully to identify and distinguish between new-onset asthmatics and those with reactivated disease. This work also demonstrates that providers attribute most asthma to infection and appear to ignore the possible contribution of environmental etiologies (occupational, home, and outdoor exposures) in the majority of cases. Annualized AOA incidence for the oneyear study period was 3.8 per 1,000 persons for new-onset cases, 4.6 per 1,000 for reactivation of asthma after at least one year of inactivity and 8.4 per 1,000 combined. Approximately $5 \%$ of all adult-onset asthma cases were considered to be associated with work. This is likely an underestimate given the paucity of evidence that occupation was consistently evaluated from an etiologic standpoint.

\section{Competing interests}

Supported by a research grants HL61302 from the National Heart, Lung and Blood Institute of the National Institutes of Health, 1K01-OH07608-1 from the National Institute of Occupational Safety and Health, and 2P30 ES 00002 from the National Institute of Environmental Health Sciences Occupational and Environmental Health Center.

\section{Authors' contributions}

SRS coordinated and supervised the fieldwork, conducted some chart reviews analyzed much of the data in SAS and had primary responsibilities for manuscript preparation. PRH was responsible for the final version and maintenance of the chart review software and conversion of software into SAS datasets. PC conducted the great majority of chart reviews. AM was responsible for data management/ analysis and producing SAS datasets. RR assisted with project design and management. DKM wrote the initial study design, obtained funding and supervised all aspects of the project including data analysis and manuscript preparation. PKH assisted with manuscript review.

\section{Acknowledgements}

We would like to acknowledge the Fallon Research Staff, especially Priscilla Cirillo, R.N., for without their dedication and hard work, this project would not have been possible. We thank Becky Ikehara, Frank Alexis for their assistance with front end and data warehouse issues. Supported by a research grants HL6I302 from the National Heart, Lung and Blood Institute of the National Institutes of Health, IKOI-OH07608-I from the National Institute of Occupational Safety and Health, and 2P30 ES 00002 from the National Institute of Environmental Health Sciences Occupational and Environmental Health Center.

\section{References}

I. National Heart Lung and Blood Institute: Guidelines for the diagnosis and management of asthma. National Asthma Education Program Expert Panel report. J Allergy Clin Immunl. I99I, 88:425-534.

2. Anonymous: Asthma--United States, 1982-1992. MMWR Morb Mortal Wkly Rep 1995, 43:952-955.

3. Karjalainen A, Kurppa K, Virtanen S, Keskinen $\mathrm{H}$ and Nordman $\mathrm{H}$ : Incidence of occupational asthma by occupation and industry in Finland. Am J Ind Med 2000, 37:451-458.

4. Weiss KB and Wagener DK: Asthma surveillance in the United States. A review of current trends and knowledge gaps. Chest 1990, 98:179S-184S.

5. Yunginger JW, Reed CE, O'Connell EJ, Melton Lj 3d, O'Fallon WM and Silverstein MD: A community-based study of the epidemiology of asthma. Incidence rates, 1964-1983. Am Rev Respir Dis 1992, 1 46:888-894.

6. McWhorter WP, Polis MA and Kaslow RA: Occurrence, predictors, and consequences of adult asthma in NHANES I and follow-up survey. Am Rev Respir Dis 1989, 139:721-724.

7. Kivity S, Shochat Z, Bressler R, Wiener M and Lerman Y: The characteristics of bronchial asthma among a young adult population. Chest 1995, 108:24-27.

8. Vollmer WM, Osborne ML and Buist AS: 20-year trends in the prevalence of asthma and chronic airflow obstruction in an HMO. Am J Resp and Crit Care Med 1998, 157:1079-1084.

9. Osborne ML, Vollmer WM, Linton KL and Buist AS: Characteristics of patients with asthma within a large HMO: a comparison by age and gender. Am J Resp and Crit Care Med 1998, I 57:123-128.

10. Donahue JG, Weiss ST, Goetsch MA, Livingston JM, Greineder DK and Platt R: Assessment of asthma using automated and fulltext medical records. J Asthma 1997, 34:273-281.

II. Donahue JG, Weiss ST, Livingston JM, Goetsch MA, Greineder DK and Platt R: Inhaled steroids and the risk of hospitalization for asthma. Jama 1997, 277:887-89I.

12. Milton DK, Solomon GM, Rosiello RA and Herrick RF: Risk and incidence of asthma attributable to occupational exposure among HMO members. Am J Ind Med 1998, 33:I-10.

13. Martin AJ, McLennon LA, Landau LI and Phelan PD: The natural history of childhood asthma to adult life. $\mathrm{Br}$ Med J 1980 280: $1394-1400$

14. Gerritsen J, Koeter GH, Postma DS, Schouten JP and Knol K: Prognosis of asthma from childhood to adulthood. Am Rev Respir Dis 1989, 140:1325-1330.

15. Ryssing E: Continued follow up investigation concerning the fate of 298 asthmatic children. Acta Paediatr (Uppsala) 1959, 48:255-260.

16. National Heart Lung and Blood Institute: National Asthma Education and Prevention Program. 1989 [http://www.nhlbi.nih.gov/ about/naepp/index.htm].

\section{Pre-publication history}

The pre-publication history for this paper can be accessed here:

http://www.biomedcentral.com/content/backmatter/ 1476-069x-2-10-b1.pdf 